\title{
Pattern Recognition Makes Search Possible: \\ Comments on Holding (1992)
}

Gobet, F., \& Simon, H. A. (1998). Pattern recognition makes search possible: Comments on Holding (1992). Psychological Research, 61, 204-208

\author{
Fernand Gobet \\ ESRC Centre for Research in \\ Development, Instruction and Training \\ University of Nottingham
}

Herbert A. Simon

Carnegie Mellon University

\author{
Send correspondence to \\ Fernand Gobet \\ Department of Psychology \\ University of Nottingham \\ Nottingham NG7 2RD \\ United Kingdom \\ Phone: (0115) 9515402 \\ Fax: (0115) 9515324 \\ frg@psyc.nott.ac.uk
}

Running head: Pattern recognition and search 


\begin{abstract}
Chase and Simon's (1973) chunking theory of expert memory, which emphasizes the role of pattern recognition in problem solving, has attracted much attention in cognitive psychology. Holding (1992) advanced a series of criticisms that, taken together, purported to refute the theory. Two valid criticisms - that chunk size and LTM encoding were underestimatedare dealt with by a simple extension of the theory (Gobet \& Simon, 1996a). The remainder of Holding's criticisms either are not empirically founded or are based on a misunderstanding of the chunking theory and its role in a comprehensive theory of skill. Holding's alternative SEEK theory, which emphasizes the role of search, lacks key mechanisms that could be implemented by the type of pattern recognition proposed by Chase and Simon (1973).
\end{abstract}




\section{Pattern Recognition Makes Search Possible: \\ Comments on Holding (1992)}

Chase and Simon's (1973) chunking theory of expert perception, memory and problem solving (CT) has received, and continues to receive, considerable attention in cognitive psychology (e.g., Charness, 1992). In his book The psychology of chess skill (1985), and later in his paper Theories of chess skill (1992), Holding systematically criticized CT as an explanation for chess skill in particular and for expertise in general, and proposed instead the SEEK (SEarch, Evaluation, Knowledge) theory. Because of the importance of the chunking theory, a systematic review of Holding's main criticisms is warranted. After briefly presenting CT and SEEK, we shall argue that most of Holding's points are due to a misunderstanding of CT or are refuted by empirical evidence. As a consequence, CT fares better than suggested by Holding, and is substantially more valid and powerful than Holding's own theory, which was never formulated in precise operational terms.

\section{The Chunking (CT) and SEEK Theories}

This paper will focus on Holding's 1992 article, which nicely summarized the key arguments of his book. Holding (1992) described Chase and Simon's chunking theory, which he calls "recognition-association theory" as follows:

"[The chunking theory] arose from the belief that differences in forward search could be discounted. Instead, the theory suggests that chess skill depends on memory of specific patterns of pieces on the board. Essentially, grandmasters are stronger because they know more patterns." (p. 10)

and

"In more details, the recognition-association theory makes the assumption that chess mastery stems from knowing thousands of chess patterns. Recognition of 
one of these patterns during play is said to trigger the memory of an associated plausible move, which may then be selected or investigated by the player. Hence, chess skill depends on memory." (p. 10)

Holding also mentioned computer simulations carried out by Simon and Gilmartin (1973), which led to the estimate that it takes at least 50,000 chunks to produce a recall performance close to that of a master, and contested this estimate as too large.

Holding's rendition of the CT account of expert chess memory is essentially correct, although it is sketchy-for example, it says nothing about the links between CT and EPAM (Feigenbaum \& Simon, 1984; Simon \& Gilmartin, 1973), which add important information processing constraints, such as limits on the learning rate (about $8 \mathrm{~s}$ per chunk) and on the storage capacity of short-term memory (around seven chunks).

Holding was wrong, however, in asserting that Chase and Simon claimed that forward search could be discounted in the explanation of chess skill. The principal claims of the CT theory are (1) that the superiority of strong over weak chess players in memory for briefly presented chess positions and sequences of moves depends on evoking from memory previously learned, and consequently familiar, patterns (chunks) of pieces; and (2) that these same perceptual chunks also play a central role in guiding the forward search used to discover and evaluate moves and in retaining information gathered in the course of this search.

Specifically, the relation between perceptual chunks in memory and forward search is discussed explicitly by Chase and Simon (1973, pp. 268-272), and they assert both that

"When the master is staring at a chessboard trying to choose his next move, he is engaged in a forward search through some kind of problem space," and that

"When the move is made in the mind's eye - that is, when the internal representation of the position is updated-the result is then passed back 
through the pattern perception system and new patterns are perceived. These patterns in turn will suggest new moves, and the search continues."

These passages, and the discussion surrounding them, can hardly be described as discounting the role of search in chess skill. They do distinctly emphasize the importance of chess memory, and the associated perception, in carrying out such search expertly. We will have more to say about them later.

As an alternative and better theoretical explanation of chess skill, Holding proposed the SEEK theory, which emphasizes the role of search, evaluation, and knowledge. SEEK maintains that the choice of a move is based on search and on evaluation, both guided by general, and not chunk-specific, knowledge. Holding $(1985,1992)$ hardly specified his theory in more detail. For example, he did not indicate the type of data structures underlying "general knowledge" or give time parameters for the rate of searching and learning.

\section{Holding's Criticisms of the Chunking Theory: A Reanalysis}

As Holding's criticisms of CT have been frequently cited, it is worth reviewing them in detail. The data adduced in his 1992 paper, which summarizes the list of about forty contrary findings reported in Holding (1985), may be grouped into two main categories: empirical evidence on memory, and empirical evidence on problem solving. We will discuss them in turn.

\section{Empirical Evidence on Memory}

Holding proposed five sets of data as offering negative evidence for the chunking theory: (a) encoding into LTM is faster than proposed by the chunking theory; (b) the size of chunks is too small to reflect conceptual knowledge; (c) memory for random positions sometimes shows skill differences; (d) the number of 50,000 chunks necessary for expertise is inflated; and (e) verbal knowledge and processing, neglected by the chunking theory, is important.

The first criticism, backed for example by experiments showing that interpolated tasks reduce recall performance minimally (Charness, 1976; Frey \& Adesman, 1976) is one 
of the Holding's soundest. There is also substantial merit in the second point: that Chase and Simon underestimated the size of chunks (they proposed that the largest chunks would contain at most six or seven pieces), making it difficult to explain the high-level, conceptual knowledge shown by masters (e.g., De Groot, 1946/1978; Freyhoff, Gruber \& Ziegler, 1992). A recent replication and extension of Chase and Simon's experiment, carried out with a computer presentation of positions instead of a standard chess set, shows that chunks can be much larger with masters and grandmasters: up to seventeen pieces, on average (Gobet \& Simon, in press).

These two weaknesses in the original chunking theory have led recently to an extension of the theory (Gobet \& Simon, 1996a) that does not impose a limit on the size of chunks, thus removing criticism (b), and proposes that chunks that recur often evolve into more complex structures, called templates. Templates have positions for variables (slots), which allow values to be encoded and stored rapidly, hence account for the rapid LTM storage showed by chess players and remove criticism (a).

Criticism (c), backed for example by Goldin's (1979) recognition experiments, loses much of its significance now that it has been shown that CT (correctly) predicts a (small) skill difference in the recall of random chess positions (Gobet \& Simon, 1996b; Gobet \& Simon, 1996c). Criticism (d) addresses Simon and Gilmartin's (1973) estimate that it takes from 10,000 to 100,000 chunks to reach expertise in chess and in any complex domain. Holding proposed that this number can be greatly reduced if chunks encode relations between pieces but not the exact location of pieces, so that the same chunk can represent constellations of pieces that have been shifted on the board. Saariluoma (1994) and Gobet and Simon (1996b), have recently shown that chunks do encode information about the location of pieces, and that, as a consequence, Simon and Gilmartin's estimate is not inflated.

Finally, referring to data from Pfau and Murphy (1988) and Holding (1989), Holding proposed (e) that verbal knowledge and processing may play an important role in chess, contrary to the chunking theory's emphasis on visual memory. With respect to verbal knowledge, CT does not deny its role, but offers perceptual mechanisms to explain how it 
can be accessed (e.g., Chase \& Simon, 1973, p. 261). With respect to verbal processing, recent experiments using Baddeley's (1986) suppression techniques clearly show that tasks that suppress the visuo-spatial sketchpad and tasks that suppress the central executive do impair performance in chess recall or problem solving, but that articulatory tasks without such suppression do not (Robbins et al., 1995; Saariluoma, 1991; Saariluoma, 1992). (Holding himself, 1992, p. 13, correctly noted that the task of counting backwards, used in Holding (1989) as a way of interfering with verbal processing, also suppressed what corresponds to the central executive in Baddeley's terminology.) The results of these experiments clearly show that verbal processing is not essential in chess memory and thinking.

In summary, Holding was correct on two counts (role of LTM and size of chunks) and wrong on three. The two weaknesses of CT correctly identified by Holding have been removed by the revision of the theory proposed by Gobet and Simon (1996a).

\section{Empirical Evidence on Problem Solving}

As a chess player's main occupation is not to perform memory experiments but to play chess, it is important to address the role of chunks when the task is to choose a move. This brings us to the second set of Holding's criticisms. With respect to problem solving, Holding challenged CT on the grounds that (a) most chess patterns consist of pawns, ${ }^{1}$ and pawn structures do not generate many moves; (b) most chess patterns found by Chase and Simon (1973) are too small to provide useful information; (c) pattern recognition is not sufficient to explain chess skill, because it applies only to the initial moves from the stimulus position and does not take look-ahead analysis into account; (d) strong players search much deeper and wider in the tree search than was suggested by De Groot (1946) or is predicted by CT; and (e) that the production-system explanation proposed by CT has never been validated.

The claim (a) that few moves are evoked by pawn structures, is refuted by the significance that chess players attach to pawns. Their importance was recognized already in the eighteenth century by Philidor (1749), who stated that "Pawns are the soul of chess." Whole books (e.g., Euwe, 1972; Kmoch, 1980) analyze the proper way to handle pawns and 
describe typical pawn structures. Pawn structures provide information about the squares on which pieces should be placed (e.g., a Knight in front of an isolated pawn) and also typical pawn moves for given structures. Players, while thinking aloud, frequently comment on pawn structures and on moves relevant to them in problem solving tasks (see De Groot, 1946) and even in memory tasks (De Groot \& Gobet, 1996; Gobet, 1993).

The claim (b) that chunks are too small to generate useful information (Chase and Simon hypothesized chunks of at most six or seven pieces) may have some truth, although even small chunks can suggest good moves in tactical situations, and chunks or small constellations of them allow recognition of positions of particular types. Moreover, as was claimed by Holding (see above), Chase and Simon probably underestimated chunk size, especially for masters. Removal of an artifact from their experiments -- limitation of chunk size by size of handgrasp -- has provided new, substantially larger, estimates. Large chunks (templates) play an essential role in the revised theory.

The claim (c) rests on a misunderstanding of the chunking theory. Holding states that "[...] the basic assumption of the pattern-move theory [is] that the better players derive their advantage simply from considering the better base moves suggested by familiar patterns" (Holding, 1985, p. 248), where "base moves" are moves playable in the stimulus position. On the contrary, as we already noted above, Chase and Simon (1973) stated explicitly that recognition of patterns is used not only to generate base moves but also subsequent moves triggered by patterns in the "mind's eye" at deeper levels during search.

A study by Holding and Reynolds (1982) is often cited as evidence against the recognition association theory. In their study, the skill of players (from novices to experts) did not correlate with the recall of random positions ${ }^{2}$ shown for a few seconds, but effectiveness of the search for the best move in these positions did correlate with skill. However, because pattern recognition is applied recursively during look-ahead, a memory test only on the initial problem position does not really address the recognition-association assumption.

With respect to Holding's claim (d), recent empirical data support the contention that stronger chess players search slightly deeper, on average, than weaker players (Charness, 
1981; Gobet, in press; Saariluoma, 1990), but not that they search wider. It is, however, unclear to what extent the differences in average depth of search refute the chunking hypothesis: the differences are small, and the formal model described in Gobet (1997) shows that CT also predicts that strong players have a higher ability to search, even if they may not need to do so in most cases. Data reported by Chase and Simon (1973), showing that strong players also acquire longer chunks of move sequences when recalling games, would also predict, on the basis of the chunking mechanism, that they have information that enables them to search more deeply than weaker players.

Finally, Holding claims (e) that the production system account adduced by CT has never been validated. (Chase and Simon, 1973, proposed that chunks act as conditions of productions (condition --> action rules) which trigger moves upon recognition.) However, there is now a large body of empirical evidence supporting such a mechanism. For example, Saariluoma (1990) has shown that players tend to choose deeper stereotyped solutions in problems where shallower but uncommon solutions are present. (Depth is the number of moves to reach mate).

In addition, De Groot (1946) found that chess masters access information about adequate plans and position evaluation very rapidly_according to De Groot (1946), masters literally "see" the next move. No search, no application of an evaluation function is needed for a first approximation, and this automatic process is sufficient to play a reasonable game in speed chess or simultaneous games against weaker players (Calderwood, Klein \& Crandall, 1988; Gobet \& Simon, 1996d). Of course, playing a game at a professional level requires more than a first approximation and asks for search and subtle evaluations of the positions reached during this search.

CT concretely specifies the recognition mechanisms that are lacking in SEEK's account of chess skill. For example, in explaining the ability of masters to play speed chess at a high level, Holding (1992) proposed that they identify a goal rapidly and then search around this goal selectively. However, he provided no mechanism to explain how goals are identified rapidly in the first place, or what the basis is for selectivity in search. SEEK, with its emphasis on search and generality of knowledge, has difficulties explaining the speed 
with which masters "see" key aspects of a position and provides no mechanisms to account for the rapid instantiation of prototypes and other general knowledge.

In summary, none of Holding's claims on problem-solving offer evidence against the chunking theory. In addition, SEEK lacks explanatory power, as no mechanism is provided for carrying out the actions attributed to it.

\section{Conclusion}

In the summary of his paper, Holding (1992, p. 10) stated that "there is not direct support for the [chunking] theory, which omits forward search for reasons that are reexamined." This statement is incorrect on two counts. First, as we have shown here, a large amount of data supports the chunking theory, contrary to Holding's claim. Second, CT does not omit forward search nor deny its central importance for expert play in chess. Instead, it provides a mechanism—pattern recognition-that explains how selective forward search (including position evaluation) can be carried out. As mentioned above, pattern recognition occurs not only in the position on the board, but also in the various positions met during forward search.

Although often incorrect, Holding's $(1985,1992)$ criticisms have been fruitful in stimulating new empirical research that has brought about refinement of the chunking theory. In particular, Holding was correct in noting that the chunk size postulated by CT was too small, and that $\mathrm{CT}$ did not provide mechanisms allowing a rapid encoding into LTM. However, Holding's own theory, SEEK, offered only a general sketch, in itself not incompatible with the chunking theory, but insufficiently specified to make precise predictions. 


\section{Reference List}

Baddeley, A. (1986). Working memory. Oxford: Clarendon Press.

Calderwood, B., Klein, G. A., \& Crandall, B. W. (1988). Time pressure, skill, and move quality in chess. American Journal of Psychology, 101, 481-493.

Charness, N. (1976). Memory for chess positions: Resistance to interference. Journal of Experimental Psychology: Human Learning and Memory, 2, 641-653.

Charness, N. (1981). Search in chess: Age and skill differences. Journal of Experimental Psychology: Human Perception and Performance, 2, 467-476.

Charness, N. (1992). The impact of chess research on cognitive science. Psychological Research, 54, 4-9.

Chase, W. G., \& Simon, H. A. (1973). The mind's eye in chess. In W. G. Chase (Ed.), Visual information processing. New York: Academic Press.

De Groot, A. D. (1946). Het denken van den schaker. Amsterdam: Noord Hollandsche.

De Groot, A. D. (1978). Thought and choice in chess. (Revised translation of De Groot, 1946; 2nd ed.). The Hague: Mouton Publishers.

De Groot, A. D., \& Gobet, F. (1996). Perception and memory in chess. Heuristics of the professional eye. Assen: Van Gorcum.

Euwe, M. (1972). Jugement et plan. [Judgment and plan]. Paris: Payot.

Feigenbaum, E. A., \& Simon, H. A. (1984). EPAM-like models of recognition and learning. Cognitive Science, 8, 305-336.

Frey, P. W., \& Adesman, P. (1976). Recall memory for visually presented chess positions. Memory and Cognition, 4, 541-547.

Freyhoff, H., Gruber, H., \& Ziegler, A. (1992). Expertise and hierarchical knowledge representation in chess. Psychological Research, 54, 32-37.

Gobet, F. (1993). Les mémoires d'un joueur d'échecs [Chess players' memories]. Fribourg: Editions universitaires.

Gobet, F. (1997). A pattern-recognition theory of search in expert problem solving. Thinking and Reasoning, 3, 291-313. 
Gobet, F. (in press). Chess thinking revisited. Swiss Journal of Psychology.

Gobet, F., \& Simon, H. A. (1996a). Templates in chess memory: A mechanism for recalling several boards. Cognitive Psychology, 31, 1-40.

Gobet, F., \& Simon, H. A. (1996b). Recall of random and distorted positions. Implications for the theory of expertise. Memory \& Cognition, 24, 493-503.

Gobet, F., \& Simon, H. A. (1996c). Recall of rapidly presented random chess positions is a function of skill. Psychonomic Bulletin \& Review, 3, 159-163.

Gobet, F., \& Simon, H. A. (1996d). The roles of recognition processes and look-ahead search in time-constrained expert problem solving: Evidence from grandmaster level chess. Psychological Science, 7, 52-55.

Gobet, F., \& Simon, H. A. (in press). Expert chess memory: Revisiting the chunking hypothesis. Memory.

Goldin, S. E. (1979). Recognition memory for chess positions : Some preliminary research. American Journal of Psychology, 92, 19-31.

Holding, D. H. (1985). The psychology of chess skill. Hillsdale, NJ: Erlbaum.

Holding, D. H. (1989). Evaluation factors in human tree search. American Journal of Psychology, 102, 103-108.

Holding, D. H. (1992). Theories of chess skill. Psychological Research, 54, 10-16.

Holding, D. H., \& Reynolds, R. I. (1982). Recall or evaluation of chess positions as determinants of chess skill. Memory \& Cognition, 10, 237-242.

Kmoch, H. (1980). La force des pions aux échecs. [Pawn power in chess]. Paris: Payot.

Pfau, H. D., \& Murphy, M. D. (1988). Role of verbal knowledge in chess. American Journal of Psychology, 101, 73-86.

Philidor, F. A. D. (1749). L'analyse du Jeu des Echecs. [The analysis of the game of chess]. London.

Robbins, T. W., Anderson, E., Barker, D. R., Bradley, A. C., Fearnyhough, C., Henson, R., Hudson, S. R., \& Baddeley, A. D. (1995). Working memory in chess. Memory and Cognition, 24, 83-93. 
Saariluoma, P. (1990). Apperception and restructuring in chess player's problem solving. In K. J. Gilhooly, M. T. G. Keane, R. H. Logie, \& G. Erdos (Eds.), Lines of thinking, (Vol. 2, ): John Wiley Sons Ltd.

Saariluoma, P. (1991). Aspects of skilled imagery in blindfold chess. Acta Psychologica, 77, 65-89.

Saariluoma, P. (1992). Visuospatial and articulatory interference in chess players' information intake. Applied Cognitive Psychology, 6, 77-89.

Saariluoma, P. (1994). Location coding in chess. The Quarterly Journal of Experimental Psychology, 47A, 607-630.

Simon, H. A., \& Gilmartin, K. J. (1973). A simulation of memory for chess positions. Cognitive Psychology, 5, 29-46. 


\begin{abstract}
Author's note
Correspondence concerning this article should be addressed to Fernand Gobet, Department of Psychology, University of Nottingham, Nottingham NG7 2RD, England.
\end{abstract}

\title{
Footnotes
}

${ }^{1}$ Chess players differentiate between pawns, the weakest men and the remaining pieces (king, queen, rook, bishop and knight).

${ }^{2} \mathrm{~A}$ problem with this study is that the positions are not completely random. First, some (semantic) constraints were applied in generating the positions used by Holding and Reynolds (1992). Second, a statistical analysis shows that equiprobability of White and Black pieces' distribution on the board may be rejected at $\mathrm{p}<.001$ (Gobet, 1993). Therefore, the findings of this study are hard to interpret. 